\title{
BMJ Global Heath Cluster containment strategy: addressing Zika virus outbreak in Rajasthan, India
}

\author{
Ruchi Singh, ${ }^{1}$ Veenu Gupta, ${ }^{2}$ Bharti Malhotra, ${ }^{\circ}$ Sujeet Singh, ${ }^{4} \mathrm{P}$ Ravindran, ${ }^{5}$ \\ Deepa Meena, ${ }^{6}$ Jyoti Gupta, ${ }^{6}$ VK Mathur, ${ }^{6}$ Ravi Prakash Mathur, ${ }^{6}$ Sunil Singh, ${ }^{6}$ \\ Pratibha Sharma, ${ }^{3}$ Himanshu Sharma, ${ }^{3}$ Sudhir Bhandari, ${ }^{7}$ Nivedita Gupta, ${ }^{8}$ \\ Gajanan Sapkal, ${ }^{9}$ Devendera T Mourya, ${ }^{9}$ Maclane Davis Speer ${ }^{6,10}$
}

To cite: Singh R, Gupta V, Malhotra B, et al. Cluster containment strategy: addressing Zika virus outbreak in Rajasthan, India. BMJ Global Health 2019;4:e001383. doi:10.1136/ bmjgh-2018-001383

Handling editor Peter MacGarr Rabinowitz

Received 30 December 2018 Revised 25 May 2019 Accepted 1 June 2019

\section{Check for updates}

(C) Author(s) (or their employer(s)) 2019. Re-use permitted under CC BY-NC. No commercial re-use. See rights and permissions. Published by BMJ.

For numbered affiliations see end of article.

Correspondence to Dr Bharti Malhotra; DRBHARTIMALHOTRA@GMAIL. COM

\section{ABSTRACT}

India is at risk of Zika virus transmission due to high prevalence of its vector Aedes aegypti. Rajasthan, a state in the north-west region of India, has also high prevalence of Aedes mosquito. First laboratory confirmed case of Zika virus disease in Rajasthan was reported on 21 September 2018 in Jaipur. The Government of Rajasthan quickly implemented a containment strategy to contain the outbreak and prevent further spread of this disease. Strategy included active human and mosquito surveillance, laboratory testing and sequencing of the virus, integrated vector control measures, intersectoral coordination, risk communication and social mobilisation, all in a predefined geographic area around the epicentre. Timely action with appropriate coordination at all levels with multiple stakeholders contained the outbreak successfully. In all, 159 confirmed cases were reported from in and around the $3 \mathrm{~km}$ containment zone in Shastri Nagar area of Jaipur City and routine surveillance. Following this, a specially developed laboratory-based surveillance strategy was put in place to ensure that the disease does not spread beyond the containment zone. No fresh case was reported subsequently within or beyond the containment zone.

\section{INTRODUCTION}

Explosive Zika epidemic was reported from

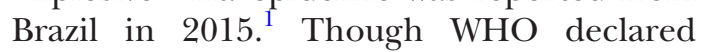
that Zika virus disease (ZVD) ceased to be a Public Health Emergency of International Concern after November 2016, but Government Of India (GOI) continued to be on high alert due to abundance of vector Aedes aegypti and high international travel from endemic countries. Indian Council of Medical Research (ICMR) initiated Zika virus (ZIKV) surveillance through its network of Virus Research and Diagnostic Labs (VRDL), with the National Institute of Virology (NIV) as the apex laboratory from year 2016. ICMR mandated testing a proportion of Dengue-negative and Chikungunya-negative samples for Zika and zeno diagnosis of Aedes

\section{Summary box}

Zika virus is known to cause major outbreaks as seen in Brazil, French Polynesia, and so on, but the four cases in India reported earlier in 2017 did not lead to major outbreak.

- First laboratory confirmed case of Zika virus disease was reported from Shastri Nagar area of Jaipur on 21 September 2018 and on extensive house-tohouse survey of the area around index case, many additional cases were detected with clustering that called for concerted effort from all concerned to contain the outbreak and prevent its further spread.

- A containment strategy inclusive of extensive active surveillance with strong laboratory support, vigorous implementation of vector control and effective communication strategy in a predefined geographic area around the epicentre can help contain the outbreak.

mosquito population. From November 2016 to March 2017, India reported its first three ZVD cases from Gujarat, ${ }^{2}$ followed by the fourth case from Tamil Nadu in 2017. ${ }^{3}$ At all these locations, the containment strategy was followed and further testing of febrile cases through routine surveillance did not suggest the circulation of ZIKV in the community.

On 21 September 2018, first laboratory-confirmed ZIKV case at Jaipur, Rajasthan was reported during routine surveillance by ICMR VRDL, SMS Medical College, Jaipur, confirmed by ICMR-NIV, Pune through realtime PCR. This 85-year-old woman, a resident of Shastri Nagar, was hospitalised on 11 September 2018 with a history of neurological disorder. There was no history of travel or fever in last 4 weeks in patient or family members. Transmission appeared to be by local vector only. Detection of ZIKV in Aedes mosquitoes in the area confirmed the same.

Shastri Nagar, the epicentre, is an urban settlement, densely populated with all income 


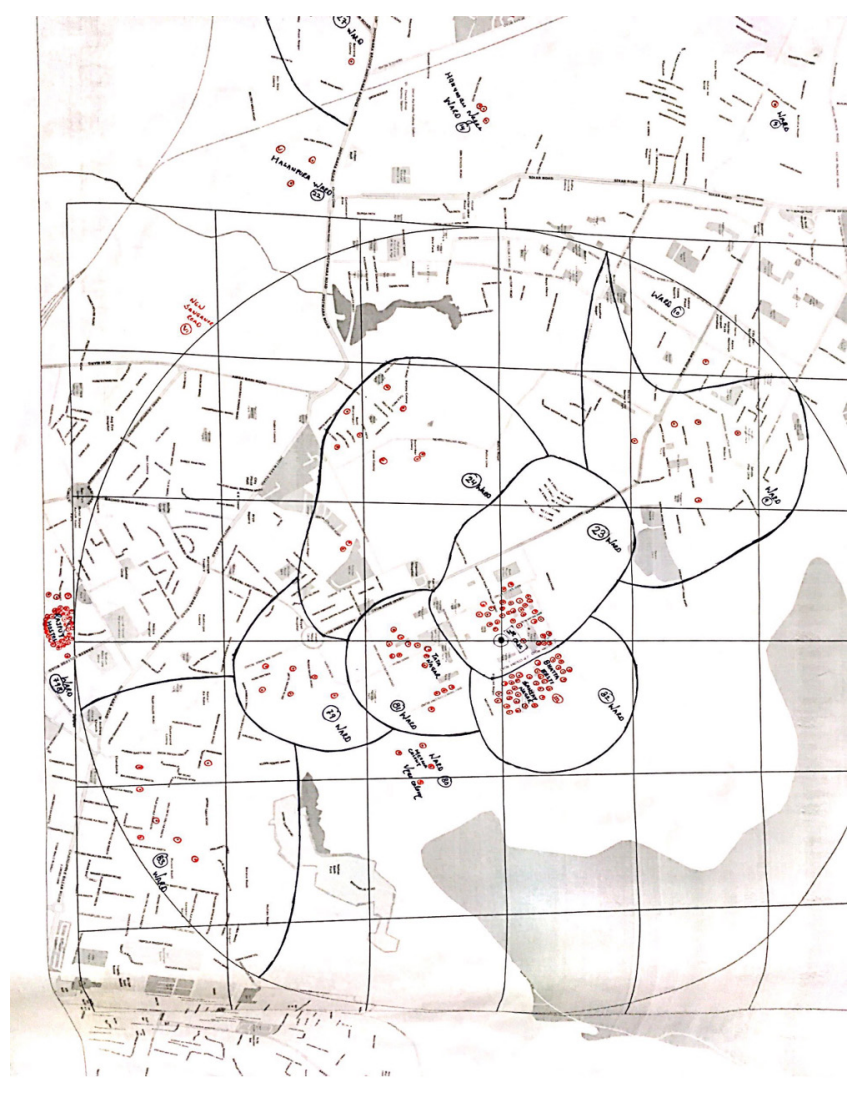

Scanned with CamScanner

Figure 1 Map of $3 \mathrm{~km}$ radius area at Shastri Nagar with respect to index case.

groups, belonging to ward 23 of Jaipur Municipal Corporation (JMC). Due to shortage of water, people stored water in underground/overground tanks leading to perennial vector breeding. Despite government's efforts on vector control, community involvement was poor leading to high vector indices, further enhanced by extended monsoon. Initially, vector indices (Container Index (CI), Household Index (HI) and Breteau Index (BI)) were above 140 .

Another epicentre was found near a boy's hostel (at periphery of first epicentre zone); additional wards surrounding this hostel were included in the containment operations. Total population of these areas was 474 725 with 96289 households.

\section{RESPONSE OF GOVERNMENT OF RAJASTHAN}

There was high level of political and administrative commitment; Additional Chief Secretary herself

Table 1 Surveillance data (from 22 September 2018 to 16 November 2018)

No of teams

8615

No of visits to houses

300268

No of fever cases identified

8878

No of pregnant women identified monitored the containment operations on daily basis, ensuring coordination with all departments. Government of Rajasthan (GOR) followed the containment strategy envisaged in the National Zika Action Plan, as per International Health Regulations 2005.

\section{Containment planning}

Microplan was prepared for the containment of ZIKV. The epicentre and area within $3 \mathrm{~km}$ radius $\left(29 \mathrm{~km}^{2}\right)$ around this epicentre was mapped (figure 1), team of two health workers attended to 50 households, and 350-375 teams constituted from different departments; health, medical education, Integrated Child Development Services, JMC and nursing colleges for surveillance and vector control measures, its logistics were mobilised as per guidelines. ${ }^{4}$

\section{Surveillance}

Active house-to-house surveillance was done in the area to detect, monitor and manage current cases, identify at-risk pregnancies (table 1). Routine laboratory surveillance was scaled up to test samples of febrile cases and antenatal mothers outside the containment zone.

Entomological surveillance was done daily; six teams of entomologist visited the households and daily vector indices (CI, HI and $\mathrm{BI}$ ) were monitored; aim was to attain larval indices less than $5 \%$ to successfully break the chain of transmission. ${ }^{5}$

\section{Surveillance for microcephaly}

Zika has been known to affect foetal brain resulting in microcephaly. ${ }^{6-8}$ GOI has an ongoing programme for the detection of birth defect in newborn. Jaipur, VRDL is site for surveillance. No increase in the incidence of microcephaly was noted before the outbreak. Surveillance among antenatal mothers was enhanced, with ultrasonography at the 18-20 weeks and 28 weeks.

\section{Laboratory testing}

Laboratory testing was done at VRDL, SMS Medical College, Jaipur; five VRDL at Rajasthan were also trained to carry out routine surveillance for ZIKV and did not report any ZIKV-positive sample.

Urine and blood samples were tested as per WHO guidelines. ${ }^{9}$ Quality assurance was ensured by NIV, Pune. Initially, all suspected fever cases, contacts and pregnant mothers were tested. Later strategy was changed to test only $10 \%$ suspects with fever, all first trimester, and only symptomatic second and third trimester pregnant women.

Among 2043 samples collected from the area (table 2), 153 patients were found positive, 6 additional from routine surveillance at SMS Jaipur, in total 159 patients tested positive for ZIKV.

\section{Case management}

Six medical teams assessed the suspected cases detected by the health workers. Those requiring hospitalisation were shifted to separate health facility with mosquito proofed isolation wards. Counselling was done to use 
Table 2 Details of samples tested and positivity for Zika virus in house-to-house survey

\begin{tabular}{lccc}
\hline Category tested & Number tested & Positive & $\%$ \\
\hline Fever patients & 756 & 90 & 11.9 \\
Pregnant women & 1171 & 62 & 5.3 \\
Contacts & 116 & 1 & 0.86 \\
Total & 2043 & 153 & 7.5 \\
\hline
\end{tabular}

mosquito repellents, long-lasting insecticidal nets, and not to donate blood during illness. Safe sexual contact and avoidance of pregnancy for a period of 6 months were suggested to at-risk couples, counselled regarding the risks associated with ZVD.

Two positive women delivered healthy infants with no evidence of Zika infection in amniotic fluid, vaginal discharge and cord blood.

\section{Vector management}

Antiadult, antilarval and source reduction measures in the affected area were done as per National Vector Borne Disease Control Programme (NVBDCP). Three rounds of fogging with cyphenothrine $5 \mathrm{EC}$ (dose: $7 \mathrm{~mL} / \mathrm{L}$ diesel) was done to knockdown adult mosquitoes. Indoor residual spray (IRS) with synthetic pyrethroid was in and around houses of positive cases, while indoor space spray using pyrethrum extract $2 \%$ was done in whole area. Antilarval activities were done by chemical (temephos and mosquito larvicidal oil) and biological control (table 3).

Vigorous vector control successfully decreased vector indices in the containment zone and adjoining wards. The HI reduced from 8 to 75 to $0-1.36$ and BI reduced from 14 to 124 to $0-1.4$ (figure 2 ).

\section{Risk communication}

The risk communication material was prepared in local language and distributed in containment zone and rest of Jaipur. Community was informed on vector control and protection measures using miking, local FM, TV channels and print media. School children and local volunteers were identified and trained regarding the identification of larvae and source reduction methods; their database has been maintained for future use.

\section{Control room}

Control room was established at Shastri Nagar, for team formation, their daily briefing, data collection,

\begin{tabular}{ll}
\hline Table 3 Vector control activities & \\
\hline $\begin{array}{l}\text { No of breeding sites checked } \\
\text { No of containers positive for } \\
\text { breeding }\end{array}$ & 1317648 \\
\hline $\begin{array}{l}\text { Source reduction } \\
\text { Temephos treatment }\end{array}$ & 90339 \\
\hline Focal spray & 35505 containers \\
\hline
\end{tabular}

compilation and analysis, sample drop-off and logistics management.

\section{Oversight mechanism}

Supervisory teams supervised the containment operations, and $5 \%-10 \%$ of previously checked houses were crosschecked by them. Fine was imposed by JMC on households and establishments resisting the surveillance and control programme. Zika-positive pregnant women were being monitored for birth defects.

A mid course review was done by senior officers of GOR and GOI for wards with BI $>20$. Vector control procedures were revised to include IRS with synthetic pyrethroid and outdoor fogging by cyphenothrin $5 \mathrm{EC}$ (dose: $7 \mathrm{~mL} / \mathrm{L}$ diesel).

Last positive case was reported on 28 October 2018, and containment operations continued for another 2 weeks under strict monitoring. A surveillance plan was implemented in Jaipur city outside the containment zone also.

\section{Support by Government of India}

Ministry of Health and Family Welfare, GOI provided technical and financial support to the state and reviewed the preparedness of state for the management of ZIKV. Central rapid response teams were deployed supported by various institutions that included Emergency Medical Relief of Directorate General of Health Services, National Centre for Disease Control (NCDC), All India Institute of Medical Sciences, ICMR-National Institute of Malaria Research (NIMR), ICMR-National Institute of Epidemiology, Chennai and the NVBDCP. The Strategic Health Operations Centre at NCDC was activated for daily monitoring of the outbreak and issuance of situation reports.

\section{CONCLUSION}

Sudden detection of first Zika virus case threw multiple challenges before the public health system. Quick formulation and implementation of the containment plan, mobilisation of adequate human resources, active surveillance in the defined geographical area and vector control contained the virus, reduced the vector indices from over 100 to $0-1.4$ in the operational area. Change in seasonal temperature may have facilitated fall in vector indices. Monitoring was initiated for pregnant women and appropriate advisories issued. Though no new cases have been reported from the affected area and other districts, there is need to scale up routine surveillance of ZIKV at Jaipur and throughout the country for early detection and containment.

\section{Author affiliations}

${ }^{1}$ Medical \& Health GOR, State Microbiologist IDSP Directorate, Medical \& Health Services, Jaipur, India

${ }^{2}$ Medical \& Health, Government of Rajasthan, Jaipur, India

${ }^{3}$ Microbiology, SMS Medical College and Hospital, Jaipur, India

${ }^{4}$ National Centre for Disease Control, Ministry of Health and Family Welfare,

Government of India, Delhi, India

${ }^{5}$ Emergency Medical Relief, Union Government, New Delhi, India 


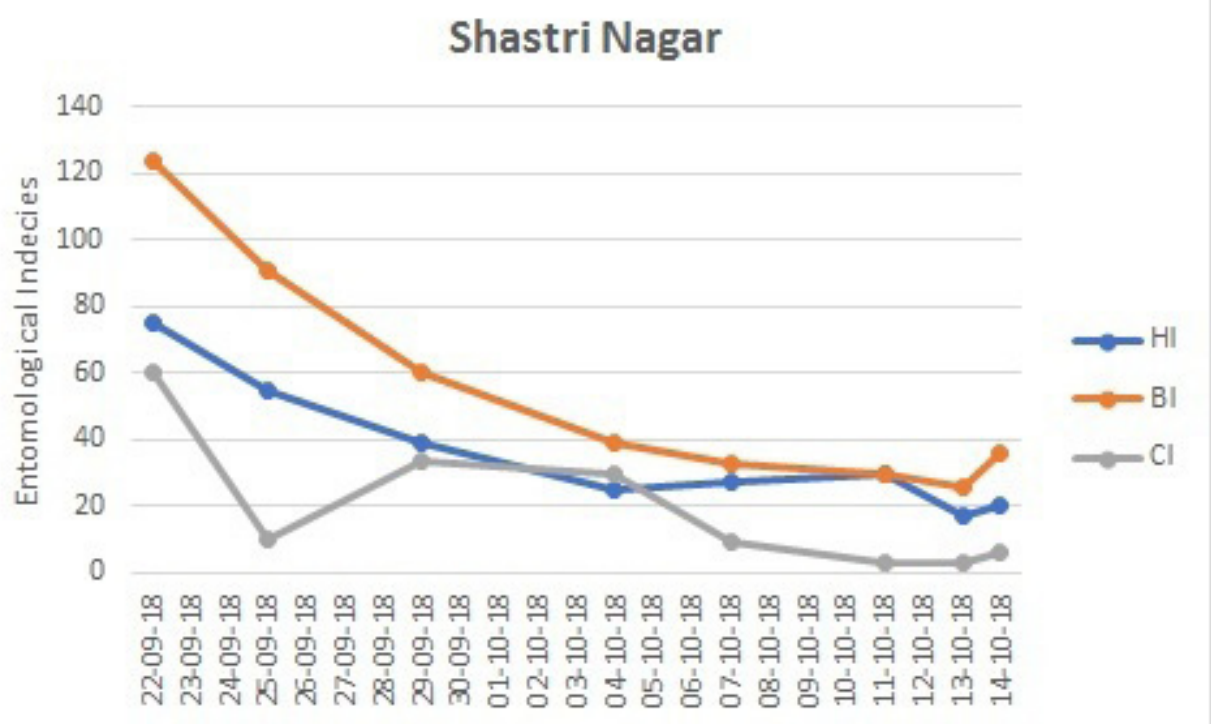

Figure 2 Municipal Ward wise progression of Container Index (Cl), Household Index ( $\mathrm{HI})$ and Breteau Index (BI) in Surveillance Zone.

${ }^{6}$ Directorate Medical \& Health, Government of Rajasthan, Jaipur, India

${ }^{7}$ Medicine, SMS Medical College and Hospital, Jaipur, India

${ }^{8}$ Epidemiology \& communicable diseases, Indian Council of Medical Research, Government of India, Delhi, India

${ }^{9}$ Virology, National Institute of Virology, Pune, India

${ }^{10}$ Public Health, Dickinson College, Carlisle, Pennsylvania, USA

Acknowledgements The authors would like to acknowledge the support and encouragement of the following: DB Gupta, Chief Secretary GOR; Preeti Sudan, Secretary Health GOI; Balram Bhargava Secretary DHR \& DG ICMR; Naveen Jain, MD, NHM; Siddharth Mahajan, District Collector; Rajan Vishal, Director IEC; Mahaveer Prasad, MD, RMSCL; Ajay Aswal, JS Group-II; Tribhuwanpati, JS, NHM; Rakesh Sharma, Add Dir; Narrotam Sharma, CMHO; Harisankar Deputy CMHO; Abhimanyu Nandu; and Kushpal Rathore, Kusum Gaur PHOD PSM. Special thanks to R.R. Gangakhedkar ICMR, AC Dhariwal Advisor NVBDCP, Himmat Singh NIMR, Ashutosh Bishwas, AllMS, State and District IDSP team as well as Municipal Corporation for their kind support. They thank all health workers and community members (including the families of those afflicted) for their support of this investigation and control programme.

Contributors RS: conceived and drafted manuscript; VG: conceived the containment strategy, edited and approved the manuscript; BM: conceived the work and edited the manuscript; first three authors contributed equally to the manuscript. SS: conceived the work and edited the manuscript; VKM, RPM: planned and executed containment strategy; DM, JG, SS: helped in the acquisition of data, PR: planning and supervising containment strategy; NG: planning surveillance and containment strategy; PS, HS: helped in data acquisition and testing; SB: helped in planning strategy; GS and DTM: planning and executing surveillance strategy; MDS: helped in drafting the manuscript.

Funding The authors have not declared a specific grant for this research from any funding agency in the public, commercial or not-for-profit sectors.

Competing interests None declared.

Patient consent for publication Not required.

Ethics approval From ethics committee of SMS Medical College \& Hospital Jaipur, sanction letter no 2583MC/EC/2016 dt 28/7/2016.

Provenance and peer review Not commissioned; externally peer reviewed.
Data availability statement No additional data are available.

Open access This is an open access article distributed in accordance with the Creative Commons Attribution Non Commercial (CC BY-NC 4.0) license, which permits others to distribute, remix, adapt, build upon this work non-commercially, and license their derivative works on different terms, provided the original work is properly cited, appropriate credit is given, any changes made indicated, and the use is non-commercial. See: http://creativecommons.org/licenses/by-nc/4.0/.

\section{REFERENCES}

1. de Oliveira WK, de França GVA, Carmo EH, et al. Infection-Related microcephaly after the 2015 and 2016 Zika virus outbreaks in Brazil: a surveillance-based analysis. The Lancet 2017;390:861-70.

2. Sapkal GN, Yadav PD, Vegad MM, et al. First laboratory confirmation on the existence of Zika virus disease in India. $J$ Infect 2018;76:314-7.

3. The Hindu. Tamil Nadu reports first case of Zika. Available: http:// www.thehindu.com/news/national/tamil-nadu/tamilnadureports-firstcase-of-zika-virus/article19254690.ece [Accessed 30 Sep 2017].

4. MOHFW. National guidelines for Zika virus disease. Available: https:// mohfw.gov.in/media/disease-alerts/national-guidelines-zika-virusdisease [Accessed 10 Dec 2018]

5. NVBDCP. Manual on integrated vector management, India Directorate of national vector borne disease control programme (Directorate G H.S., MOH \& FW, Government of India). Available: http:// www.nvbdcp.gov.in [Accessed 27 Apr 2019].

6. Cauchemez S, Besnard M, Bompard P, et al. Association between Zika virus and microcephaly in French Polynesia, 2013-15: a retrospective study. The Lancet 2016;387:2125-32.

7. Schuler-Faccini L, Ribeiro EM, Feitosa IML, et al. Possible association between Zika virus infection and microcephaly - Brazil, 2015. MMWR Morb Mortal Wkly Rep 2016;65:59-62.

8. Coelho A, Crovella S. Microcephaly prevalence in infants born to Zika virus-infected women: a systematic review and meta-analysis. Int $J$ Mol Sci 2017;18:1714.

9. World Health Organization. Interim guidance on laboratory testing for Zika virus infection. WHO/ZIKA/LA/16.1. Available: https://www.who. int/csr/resources/publications/zika/laboratory-testing/en/ [Accessed 27 Nov 2018]. 